\title{
Oral health and liver function in children and adolescents with cirrhosis of the liver
}

\author{
Dorota Olczak-Kowalczyk ${ }^{1}$, Wojciech Kowalczyk², Ewa Krasuska-Sławińska ${ }^{3}$, Maciej Dądalski, \\ Krzysztof Kostewicz ${ }^{5}$, Joanna Pawłowska ${ }^{4}$ \\ ${ }^{1}$ Department of Paediatric Dentistry, Warsaw Medical University, Poland \\ 2Private practice, Warsaw, Poland \\ ${ }^{3}$ Department of Oral Pathology, Children's Memorial Health Institute, Warsaw, Poland \\ ${ }^{4}$ Department of Gastroenterology, Hepatology and Nutritional Disorders, Children's Memorial Health Institute, Warsaw, Poland \\ ${ }^{5}$ Medical student, Warsaw Medical University, Poland
}

Prz Gastroenterol 2014; 9 (1): 24-31

DOI: $10.5114 / p g .2014 .40846$

Key words: mucosal lesions, enamel defects, gingivitis, cirrhosis of the liver, children.

Address for correspondence: Dorota Olczak-Kowalczyk MD, Department of Paediatric Dentistry, Warsaw Medical University, 18 Miodowa St, 00-346 Warsaw, Poland, phone/fax: +48 2250220 52, e-mail: do-k@o2.pl

\begin{abstract}
Introduction: People with cirrhosis of the liver are predisposed to developing oral lesions. The occurrence and type of lesion depend on the degree of liver function impairment and its type, and on the severity and duration of systemic diseases. In children, the age at which the early symptoms of liver disease are experienced is also of great importance.

Aim: To assess the prevalence of oral pathological lesions in children and adolescents with cirrhosis of the liver, and their correlation with the degree of liver function impairment.

Material and methods: Clinical and laboratory results of liver function tests (Model of End-Stage Liver Disease/Score of Paediatric End-Stage Liver Disease, Child-Pugh score) were assessed in 35 patients with cirrhosis of the liver. The average age of the patients was $10.7 \pm 4.74$ years. All patients also had their oral cavities examined (mucosa, gingiva $-\mathrm{Gl}$, hygiene $-\mathrm{PLI}$, teeth - dmft/dmfs and DMFt/DMFs, DDE Index and Candida spp. presence) and this was then correlated to the degree of liver function impairment.

Results: According to the Child-Pugh scale, 16 patients were class A and 19 were class B/C. Jaundice during the first 3 years of life occurred in 9 patients. Mucosal lesions were found in 26 out of 35 patients (74\%), including 10 out of 16 (63\%) in Child-Pugh group A, and 16 out of 19 (84\%) in group B/C (NS - non significant). Oral candidiasis occurred more often in class B/C than in class A (47.4\% vs. $12.5 \% ; p<0.05)$. The Gl index (Gingival Index) and PLI index (Dental Plaque Index) did not differ between the groups (A vs. B/C) but correlated in the whole group $(R=0.58)$ as well as in subgroups $\mathrm{A}(R=0.65)$ and $\mathrm{B} / \mathrm{C}$ $(R=0.59)$. Dmft/dmfs and DMFt/DMFs indexes did not differ between groups A and B/C, and neither did the DMFt/DMFs in patients with/without enamel defects.

Conclusions: Oral mucosal lesions are commonly found in children with cirrhosis of the liver. Advanced liver disease promotes oral candidiasis. Severity of gingivitis correlates with the presence of dental plaque.
\end{abstract}

\section{Introduction}

The oral cavity, a vital part of the human body, is an important source of information about the health of an individual. Oral lesions may manifest early, concomitant with a systemic disease, disappearing with general health improvement, or later persisting in spite of disease remission, and usually presenting developmental abnormalities. The prevalence of chronic liver disease in children and adolescents has not been determined; however, the necessity to provide treatment i.e. to per- form liver transplants in children and adolescents, was estimated at 2 per 10000 births [1].

Clinical manifestations of liver failure depend on the degree of organ damage. Compensated cirrhosis may not present any noticeable clinical features. In decompensated cirrhosis, the patient develops jaundice, symptoms of malnutrition, ascites, oedema, oesophageal varices and coagulation disorders [2]. Additionally, underlying diseases in cirrhosis of the liver may manifest, and drug side effects may occur, for example 
after glucocorticosteroid or other immunosuppressant administration in autoimmune liver disease [2-4]. The aforementioned conditions also influence oral health. They may disturb dental development and may contribute to dental caries, periodontal disease and oral mucosa lesions. Lesion type and severity depend on the age of the child when the systemic disorders started, their type and duration, as well as their impact. The oral cavity appears to be significantly affected by malnutrition, cholestasis, immunodeficiency and coagulopathy [5]. The risk of cirrhotic manifestations depends on the severity of liver impairment. Two basic scores, MELD (Model of End-Stage Liver Disease) and PELD (Score of Paediatric End-Stage Liver Disease), and the Child-Pugh score $[6,7]$ are used to assess liver functions in order to determine organ transplant indications in children under the age of 12 years [8,9].

The MELD score is affected by the prothrombin index, and bilirubin and creatinine concentrations, whereas the PELD score depends on child age, degree of malnutrition, blood, bilirubin and albumin concentra- tions and prothrombin index. The formula is complex, so to compute the scores a calculator available at www. unos.org/resourses was used. The higher the score, the more urgent the liver transplant. The Child-Pugh score assesses clinical parameters, i.e. encephalopathy and ascites, and lab results, i.e. bilirubin and albumin concentrations, and prothrombin index. On scale A (5-6 points) a one-year patient survival rate accounts for $84 \%$, on scale B (7-9 points) it accounts for $62 \%$, on scale C (10-15 points) it is $42 \%$.

\section{Aim}

The purpose of the study was to assess the prevalence of oral lesions in patients with cirrhosis of the liver, and the correlations between lesions and liver disease stages.

\section{Material and methods}

Thirty-five patients with cirrhosis (18 boys and 17 girls) aged 18 months to 18 years (mean \pm SD: 10.7 \pm 4.74 years) were enrolled to the present study. They

Table I. Selected biochemical parameters and the PELD/MELD values in groups $A$ and $B$

\begin{tabular}{|c|c|c|c|c|c|c|}
\hline \multirow[t]{2}{*}{ Parameter } & \multirow[t]{2}{*}{ Group } & \multirow[t]{2}{*}{ Mean } & \multirow[t]{2}{*}{ Median } & \multicolumn{2}{|c|}{ Quartile } & \multirow{2}{*}{$\begin{array}{l}\text { Standard } \\
\text { deviation }\end{array}$} \\
\hline & & & & Lower & Upper & \\
\hline \multirow{2}{*}{ PELD/MELD } & A & 6.19 & 7.50 & 2.50 & 10.00 & 7.40 \\
\hline & $B$ & 15.53 & 14.00 & 11.00 & 18.00 & 7.33 \\
\hline \multirow{2}{*}{ Haemoglobin [mg/dl] } & A & 11.27 & 11.15 & 10.65 & 12.65 & 1.78 \\
\hline & $B$ & 11.05 & 11.20 & 9.30 & 12.70 & 1.85 \\
\hline \multirow{2}{*}{ Haematocrit [\%] } & A & 33.71 & 33.70 & 31.55 & 38.50 & 5.62 \\
\hline & B & 31.52 & 32.40 & 28.10 & 36.70 & 8.34 \\
\hline \multirow{2}{*}{$\begin{array}{l}\text { Protein } \\
\text { total }[\mathrm{mg} / \mathrm{dl}]\end{array}$} & A & 72.99 & 75.45 & 67.50 & 77.35 & 5.46 \\
\hline & B & 66.23 & 66.80 & 60.40 & 73.70 & 10.61 \\
\hline \multirow{2}{*}{ Albumins [mg/dl] } & A & 40.21 & 40.37 & 37.10 & 43.66 & 5.68 \\
\hline & B & 33.73 & 30.89 & 28.84 & 39.27 & 7.86 \\
\hline \multirow{2}{*}{$\mathrm{INR}^{*}$} & A & 1.22 & 1.17 & 1.09 & 1.26 & 0.28 \\
\hline & $\mathrm{B}$ & 1.53 & 1.33 & 1.11 & 1.55 & 0.80 \\
\hline \multirow{2}{*}{ Total bilirubin [mg/dl] } & A & 1.24 & 0.92 & 0.74 & 1.43 & 0.80 \\
\hline & $B$ & 8.31 & 4.10 & 2.44 & 8.20 & 10.48 \\
\hline \multirow{2}{*}{ Direct bilirubin $[\mathrm{mg} / \mathrm{dl}]$} & $A$ & 0.54 & 0.32 & 0.24 & 0.63 & 0.53 \\
\hline & $\mathrm{B}$ & 5.13 & 2.09 & 0.90 & 4.70 & 7.15 \\
\hline \multirow{2}{*}{$\mathrm{ALT}[\mathrm{U} / \mathrm{I}]$} & $A$ & 145.81 & 52.00 & 38.00 & 87.00 & 231.88 \\
\hline & $B$ & 261.58 & 70.00 & 48.00 & 138.00 & 730.15 \\
\hline \multirow{2}{*}{ GGTP $[\mathrm{U} / \mathrm{I}]$} & $A$ & 98.00 & 74.00 & 41.50 & 141.00 & 78.82 \\
\hline & $B$ & 118.32 & 95.00 & 76.00 & 159.00 & 65.96 \\
\hline \multirow{2}{*}{ Creatinine $[\mathrm{mg} / \mathrm{dl}]$} & A & 0.82 & 0.50 & 0.40 & 0.70 & 0.87 \\
\hline & $B$ & 0.53 & 0.50 & 0.39 & 0.70 & 0.22 \\
\hline
\end{tabular}

INR - international normalised ratio 
were followed up at the Outpatient Clinic of Liver Diseases and Transplantology, and the Department of Oral Pathology, The Children's Memorial Health Institute, Warsaw.

The Child-Pugh Score, which assesses liver function, was used to select two groups of patients:

- group A - 16 patients qualified as class A (mean age $10.25 \pm 4.68$; median 10.5 years).

- group B - 19 patients qualified as class B/C (mean age $11.51 \pm 4.85$; median 11.16 years).

Liver function parameters for both groups are presented in Table I. Ten patients were treated with prednisone and azathioprine, and eight had jaundice in the first 3 years of life.

Oral and general clinical examinations were performed, and the results were statistically analysed.

\section{General health}

General assessment included current liver function tests, jaundice during the first three years of life (based on a retrospective analysis of patient medical records), and immunosuppressive treatment (prednisone and azathioprine). The Child-Pugh score was used to assess liver functions.

\section{Oral health}

Clinical examinations were performed to assess oral mucosa, hygiene, gingiva and teeth. Oral mucosa assessment included lesion prevalence, type and site, and was based on the WHO Guide to Epidemiology and Diagnosis of Oral Mucosal Diseases [10-12]. Clinical results were subsequently verified with mycological tests.

Oral hygiene was assessed using the Löe and Silness dental plaque index (PLI) [13]. The assessment focussed on the prevalence and amount of dental plaques in 6 teeth, i.e. 16, 12, 24, 36, 32 and 44 (in deciduous dentition: 55, 51, 63, 75, 71 and 83), according to the following scale: 0 - no plaque, 1 - thin deposit, visible on probing along the gingival margin, 2 - deposit seen by naked eye and 3 - thick plaque layer filling the interdental space. The index value calculated for each patient was the quotient of the sum of the values assessed for each surface of the assessed teeth (medial, distal, buccal and lingual) and the total number scored surfaces.

Gingival health was assessed with the Löe and Silness Gingival Index (GI) [13]. The assessment included the gingivae around all the surfaces of the evaluated teeth using PLI: 0 - no inflammation, normal gingiva; 1 - mild inflammation, a slight change in gingival colour and mild tissue structure abnormalities, no bleeding on probing; 2 - moderate inflammation, visible gloss, erythema, gingival oedema and hyperplasia, bleeding on pressure or deep probing; 3 - severe in- flammation, marked gingival erythema and oedema, susceptibility to spontaneous bleeding, ulceration.

Inflammation was assessed as mild (GI: 0.1-1.0); moderate (GI: 1.1-2.0) or severe, (GI: 2.1-3.0). Gl is a quotient of the sum of values scored for the gingivae of each assessed surface (medial, distal, buccal and lingual) and their number.

Gingival pocket depths were measured with a calibrated periodontal probe; the values recorded were those greater than $4 \mathrm{~mm}$.

Dental health was assessed based on the presence of caries and developmental disorders. Index values were calculated for DMFt/dmft (unit assessed: tooth), and DMFs/dmfs (unit assessed: tooth surface), which is the sum of all carious teeth (without precarious stages), teeth lost due to caries and filled teeth. Physiologically exfoliated teeth in patients with deciduous teeth were excluded from the study.

Dental developmental abnormalities were classified according to the DDE-Index [14]. They included: brown or grey/green discolouration, topical enamel opacity (white, yellow or brown non-transparent with a distinct barrier), dispersed opacities and hypoplasia (quantitative enamel defects).

\section{Mycological diagnostics}

Mycological material from oral mucosa (buccal and tongue) was placed in sterile test tubes (using the direct swab method). Considering the age of the youngest children, rinse samples were abandoned (due to the variation in the ages of patients, the method of oral rinsing was not applied) [12]. The clinical material was quantitatively cultured on Sabouraud solid medium. Cultures were incubated at $37^{\circ} \mathrm{C}$. The presence of fungal colonies and fungal species was assessed with the ID 32 C test (bioMeriéux) to determine their biochemical properties.

\section{Statistical analysis}

The comparative analysis between groups was done using the Mann-Whitney $U$ test for quantitative variables, and the appropriate $\chi^{2}$ test for qualitative variables. Values of $p<0.05$ were considered as significant.

\section{Results}

\section{Oral mucosa}

Mucosal lesions were found in 26 out of 35 patients (74\%): 10 out of 16 (62.5\%) in group A vs. 16 out of 19 (84\%) in group B/C - non-significant ( $p=N S$ ). The prevalence of particular oral mucosa lesions is presented in Table II. Oral candidiasis was the most common lesion, present in 2 patients in group $A$ and 9 in group $B / C$ 
Table II. Type and prevalence of lesions in the oral mucosa in children with liver failure

\begin{tabular}{|c|c|c|c|c|}
\hline \multirow[t]{2}{*}{ Variable } & \multirow[t]{2}{*}{$\begin{array}{l}\text { Total } \\
n(\%)\end{array}$} & \multicolumn{2}{|c|}{ Groups } & \multirow[t]{2}{*}{$\begin{array}{l}\text { Value of } p \\
\text { (A vs. B) }\end{array}$} \\
\hline & & $\mathrm{A}, n(\%)$ & $\mathrm{B} / \mathrm{C}, n(\%)$ & \\
\hline Patients ( $n)$ & $35(100)$ & $16(100)$ & $19(100)$ & \\
\hline Gingivitis (Gl > 0.1) & $22(62.8)$ & $10(62.5)$ & $12(63.2)$ & NS \\
\hline Mucosal lesions & $26(74.3)$ & $10(62.5)$ & $16(84.2)$ & NS \\
\hline Oral candidiasis & $11(28.6)$ & $2(12.5)$ & $9(47.4)$ & $<0.05$ \\
\hline White coating & 6 & 1 & 5 & \\
\hline Erythematous lesions & 3 & 2 & 1 & \\
\hline White coating and erythematous lesions & 2 & 0 & 2 & \\
\hline Angular cheilitis & $5(14.3)$ & $2(12.5)$ & $3(15.8)$ & NS \\
\hline Yellow, yellow-brown hyperpigmentation & $7(20.0)$ & $1(6.2)$ & $6(31.6)$ & NS \\
\hline Telangiectasia & $9(25.7)$ & $3(18.7)$ & $6(31.6)$ & NS \\
\hline Petechiae/bleeding & $7(20.0)$ & $2(12.5)$ & $5(14.3)$ & NS \\
\hline $\begin{array}{l}\text { Cheilitis with erosions or fissures and diffuse mucosal } \\
\text { erythema (atrophic stomatitis) }\end{array}$ & $7(20.0)$ & $2(12.5)$ & $5(14.3)$ & NS \\
\hline Coated tongue & $5(14.7)$ & 1 & 4 & NS \\
\hline Black tongue & $3(8.6)$ & 1 & 2 & NS \\
\hline Geographic tongue & $2(5.7)$ & 1 & 1 & NS \\
\hline Atrophic tongue & $2(5.7)$ & 0 & 2 & NS \\
\hline Fissured tongue & $2(5.7)$ & 0 & 2 & NS \\
\hline Injure erosion on tongue margin & $3(8.6)$ & 1 & 2 & NS \\
\hline Lichenoidlesions in buccal mucosa & $3(8.6)$ & 0 & 3 & NS \\
\hline $\begin{array}{l}\text { Overgrowth lesions of oral mucosa on the palate or/and } \\
\text { gingivae }\end{array}$ & $2(5.7)$ & 0 & 2 & NS \\
\hline Herpes simplex & $2(5.7)$ & 0 & 2 & NS \\
\hline Pallor & $2(5.7)$ & 0 & 2 & NS \\
\hline
\end{tabular}

$(p<0.05)$. In three patients, oral candidiasis was associated with angular cheilitis. In one child, the fungal infection affected only the labial commisure of the mouth. In 1 case of angular cheilitis, no Candida spp. was identified. Twenty per cent of patients presented various degrees of oral and gingival mucosa discolouration (cheeks and floor of the mouth) - ranging from yellow to yellowish brown or brown. Brown discolouration was found in 3 patients from group B (progressive familial intrahepatic cholestasis - PFIC, Wilson's disease and autoimmune hepatitis - $\mathrm{AlH}$ ).

$25.7 \%$ of the patients presented with telangiectasias and $20.0 \%$ with petechiae in the mucosa of the labial vestibule, cheeks, soft palate and floor of the mouth. Eleven patients (31.4\%), including 3 from group $A$ and 8 from group B, presented symptoms of nutritional deficiencies, i.e. atrophic tongue, cheilitis with erosions or fissures, diffuse erythema and pallor of the mucous membrane.
Infectious mucosal lesions occurred in both patients under and without immunosuppressants (oral candidiasis: 2 out of 10 patients under immunosuppressive therapy (20\%), and 8 out of 25 without immunosuppression (32\%); herpes simplex virus - only 2 patients without immunosuppression).

\section{Oral hygiene and gingival}

A total of $62.8 \%$ of patients had gingivitis, including $62.5 \%$ from group A and $63.2 \%$ from group B (Table II) (NS). No significant differences between PLI and GI were found when comparing groups $\mathrm{A}$ and $\mathrm{B}$ (group $\mathrm{A}: \mathrm{PLI}=$ $1.26 \pm 0.91, \mathrm{Gl}=0.52 \pm 0.61$; group $\mathrm{B}: \mathrm{PLI}=0.93 \pm 0.83$, $\mathrm{Gl}=0.64 \pm 0.73$ ) (NS) (Table III). None of them had a gingival pocket depth $>4 \mathrm{~mm}$. However PLI and GI correlated significantly in both groups - positive correlation between oral hygiene and gingival health (Table IV), and there were individuals with no or minimal gingivitis and with high PLI, or patients with a high GI and good 
oral hygiene. Gingivitis prevalence, $\mathrm{PLI}$ and $\mathrm{GI}$ were similar, independently of whether patients were undergoing immunosuppression or not (immunosuppression: 60\%, $\mathrm{PLI}=0.78 \pm 0.65, \mathrm{GI}=0.61 \pm 0.73$; without immunosuppression: $64 \%, \mathrm{PLI}=1.20 \pm 0.93, \mathrm{GI}=0.58 \pm 0.66)(\mathrm{NS})$.

\section{Dental health}

Enamel developmental abnormalities were found in 15 patients (42.8\%) in both groups: 4 out of $16(25.0 \%)$ in group $A$, and 11 out of 19 in group $B / C(57.8 \%)$ (NS)

Table III. Correlation between the oral hygiene status (PLI) and severity of gingivitis (GI) in all subjects and between groups $A$ and $B$

\begin{tabular}{cccc}
$\begin{array}{c}\text { Spearman rank } \\
\text { order correlation } \\
\text { PLI and GI }\end{array}$ & Group & $R$ Spearman & $\begin{array}{c}\text { Value } \\
\text { of } p\end{array}$ \\
\cline { 2 - 4 } & A & 0.65 & $<0.05$ \\
\hline B & 0.60 & $<0.05$ \\
\hline Total & 0.59 & $<0.05$
\end{tabular}

(Table V). Group A presented brownish green discolourations in deciduous teeth $(n=1)$, brownish green discolouration together with permanent teeth enamel opacities ( $n=1)$, and enamel opacities with permanent teeth hypoplasia $(n=2)$. In addition to brown-green discolouration of the deciduous and permanent teeth (respectively $n=3$ and $n=2$ ) and permanent teeth enamel opacities $(n=4)$, group B presented enamel opacities together with permanent teeth hypoplasia $(n=1)$ and all other types of abnormalities in permanent teeth $(n=2)$. To summarise, brownish green tooth discolouration occurred in 8 patients (22.86\%), including 4 with biliary atresia, 2 with Wilson's disease, 1 with primary sclerosing cholangitis and 1 with hepatitis of unknown aetiology. Discolouration was found in all patients who had jaundice in the first 3 years of life (100\%); however, it was only found in deciduous teeth in patients who had jaundice in infancy.

One patient presented discolouration of permanent teeth together with brown gingival discolouration (Wil-

Table IV. PLI and GLI

\begin{tabular}{|c|c|c|c|c|c|c|c|c|c|c|c|}
\hline & \multicolumn{5}{|c|}{ Group A } & \multicolumn{5}{|c|}{ Group B/C } & \multirow{2}{*}{ Value of $p$} \\
\hline & Mean & Median & Q1 & Q3 & SD & Mean & Median & Q1 & Q3 & SD & \\
\hline PLI & 1.26 & 1 & 0.5 & 2 & 0.91 & 0.93 & 0.8 & 0.25 & 1.5 & 0.83 & NS \\
\hline $\mathrm{GI}$ & 0.52 & 0.25 & 0 & 1 & 0.61 & 0.64 & 0.25 & 0 & 1.08 & 0.73 & NS \\
\hline
\end{tabular}

Table V. Hygiene status of the oral cavity (PLI), gingivae (GI) and dentition in patients with cirrhosis with reference to liver function (group A vs. group B)

\begin{tabular}{|c|c|c|c|c|}
\hline \multirow[t]{2}{*}{ Parameter } & & \multicolumn{2}{|c|}{ Group } & \multirow{2}{*}{$\begin{array}{c}\text { Mann-Whitney } \\
\text { U test } \\
\text { level " } p \text { " }\end{array}$} \\
\hline & & A & B & \\
\hline \multirow{6}{*}{$\begin{array}{l}\text { Enamel } \\
\text { defects }\end{array}$} & Brown-green discolouration & $1(\mathrm{D})$ & $3(D)+2(P)$ & NS \\
\hline & Brown-green discolouration and enamel opacity & $1(\mathrm{P})$ & 0 & NS \\
\hline & Enamel opacity & 0 & $4(P)$ & NS \\
\hline & Enamel hypoplasia and opacity & $2(P)$ & $1(P)$ & NS \\
\hline & Any type of lesion (discolouration, opacity, hypoplasia) & 0 & $1(\mathrm{P})$ & NS \\
\hline & Total, $n(\%)$ & $4(25.0)$ & $11(57.8)$ & NS \\
\hline Caries & Caries-free subjects $(\mathrm{dmf} / \mathrm{DMF}=0)$ & $1(\mathrm{M})$ & 0 & NS \\
\hline
\end{tabular}

Table VI. Dental status in Child-Pugh, various groups

\begin{tabular}{|c|c|c|c|c|c|c|c|c|c|c|c|}
\hline & \multicolumn{5}{|c|}{ Group A } & \multicolumn{5}{|c|}{ Group B/C } & \multirow{2}{*}{$\begin{array}{c}\text { Value } \\
\text { of } p\end{array}$} \\
\hline & Mean & Median & Q1 & Q3 & SD & Mean & Median & Q1 & Q3 & SD & \\
\hline $\mathrm{dmft}$ & 7.33 & 7 & 5 & 9 & 4.85 & 4.11 & 3 & 2 & 4 & 4.78 & NS \\
\hline dmfs & 16.56 & 20 & 9 & 24 & 10.33 & 10.50 & 4 & 3 & 14.5 & 13.48 & NS \\
\hline DMFt & 8.92 & 5 & 2 & 13 & 8.38 & 12.13 & 12.5 & 5 & 18 & 7.88 & NS \\
\hline DMFs & 15.09 & 6 & 1 & 33 & 19.00 & 28.67 & 19 & 6 & 37 & 30.23 & NS \\
\hline
\end{tabular}


Table VII. Dental status and immunosuppression

\begin{tabular}{|c|c|c|c|c|c|c|c|c|c|c|c|}
\hline & \multicolumn{5}{|c|}{ Immunosuppression } & \multicolumn{5}{|c|}{ No immunosuppression } & \multirow{2}{*}{$\begin{array}{c}\text { Value } \\
\text { of } p\end{array}$} \\
\hline & Mean & Median & Q1 & Q3 & SD & Mean & Median & Q1 & Q3 & SD & \\
\hline PLI & 0.78 & 0.80 & 0.25 & 1.00 & 0.65 & 1.20 & 1.00 & 0.50 & 2.00 & 0.93 & NS \\
\hline $\mathrm{dmft}$ & 7.75 & 6.50 & 4.00 & 11.50 & 5.91 & 5.14 & 3.50 & 2.00 & 8.00 & 4.74 & NS \\
\hline $\mathrm{dmfs}$ & 13.75 & 11.50 & 6.50 & 21.00 & 10.34 & 13.69 & 15.00 & 2.00 & 24.00 & 12.78 & NS \\
\hline DMFt & 13.56 & 13.00 & 5.00 & 20.00 & 8.75 & 9.40 & 7.50 & 2.00 & 15.50 & 7.71 & NS \\
\hline DMFs & 31.25 & 19.00 & 5.50 & 41.50 & 37.40 & 19.22 & 8.00 & 6.00 & 36.00 & 20.26 & NS \\
\hline GI & 0.61 & 0.25 & 0.00 & 1.08 & 0.73 & 0.58 & 0.25 & 0.00 & 1.00 & 0.66 & NS \\
\hline
\end{tabular}

son's disease), and 2 presented a yellowish oral mucosa (Wilson's disease and biliary cirrhosis). Enamel opacities and hypoplasia were only found in permanent teeth.

Caries did not occur in only 1 child from group $A$. The intensity of caries was high in both groups (Table VI). Dmft, dmfs, DMFt and DMFs did not present any significant differences between the groups (A vs. B/C). Also, DMFt and DMFs did not present any significant differences in children with or without immunosuppresion (Table VII).

\section{Discussion}

The results of the present study show a high incidence of oral lesions in patients with cirrhosis of the liver. Up-to-date publications suggest children with liver failure are more prone to oral mucosa lesions than generally healthy children, which might result from hypoproteinaemia, coagulopathy, malnutrition, cholestasis or immunodeficiencies $[5,15]$. In previous studies by Olczak-Kowalczyk et al. the prevalence of angular cheilitis (36.4\% vs. $17.59 \%)$, strawberry lips with erosions (31.2\% vs. $7.5 \%)$ and geographic or smooth tongue, petechiae and yellow discolouration was statistically significant [15].

Oral candidiasis and angular cheilitis, telangiectasias, petechiae, oral mucosa yellowish and atrophic tongue, cheilitis with erosions or fissures, and diffuse erythema or oral mucosa pallor were most frequently encountered in patients with class B/C liver failure, who also frequently presented protein-calorie malnutrition, cholestasis and coagulopathy. There was only a correlation between organ function and oral candidiasis. In patients with advanced liver disease, coagulopathy associated with plasma deficiency of coagulation factors and thrombocytopenia may cause petechiae and spontaneous gingival bleeding. Bleeding disorders, petechiae, increased vulnerability to bruising, and gingival bleeding were described in patients with liver dysfunctions $[4,16]$.
Malnutrition accompanying liver failure manifests as qualitative deficits and infections. Typical symptoms of malnutrition (particularly vitamin B and iron deficiency), such as cheilitis, angular fissures, and glossitis in children with chronic liver diseases, were reported by other researchers [17].

As is generally known, malnutrition is also one of the aetiological factors in immunocompromised patients, predisposing them to infectious lesions [18]. The immunodeficiency level in patients with liver failure depends on a number of factors, including underlying diseases, treatment (immunosuppressants, glucocorticoids) as well as the level of organ impairment (malnutrition, cholestasis) [19]. According to studies, adult patients frequently develop oral infections caused by Herpes virus simplex and Candida spp. [16], and nasal infections caused by Staphylococcus aureus [19]. However, no paediatric cases were reported. The present study confirms a more frequent prevalence of fungal infections and labial herpes in patients with class B/C liver impairment. No significant differences were noted in the prevalence and intensity of gingivitis related to liver function. However, a close correlation with the presence of dental plaque was found. There was no significant correlation between GI indexes and oral candidiasis, and immunosuppression. This may be due to the low number of patient groups. Similarly, there was no correlation between prednisone and azathioprine use, and mucosal lesions in children with secondary immunodeficiencies [15]. Nevertheless, those abnormalities might be significantly less visible in children than in adults, because of different liver failure causes, smoking, different eating habits and the topical effect of alcohol on gingival tissue. In the study by Novacek et al. conducted on adults with cirrhosis, the most intense oral lesions were found in patients with alcoholic cirrhosis [5]. Guggenheimer et al. confirmed that $58 \%$ of adult liver transplant candidates had one or more oral mucosa abnormalities (fissured tongue $-37 \%$, atrophy of the tongue papillae $-18 \%$, angular cheilitis $-4 \%$, candidiasis - 2\%) [20]. Patients with cirrhosis of the liver 
presented with oral lichen planus (OLP) and oral lichen reactions (OLR). These could be caused by chronic liver disease, underlying conditions, viral infections, drugs, dental materials and stress [4, 20]. Although the study by Nellithady et al. showed no significant correlation between oral lichen planus and liver disease [21], the present study encountered lichenoid lesions in the oral mucosa of patients with advanced cirrhosis of the liver.

Hyperbilirubinaemia (> $2.5 \mathrm{mg} / \mathrm{dl}$ ) is associated with a yellowish discolouration of the sclera, mucous membrane and skin [22]. Partial bilirubin oxidation in blood may produce a darker tissue discolouration, i.e. greenish brown or yellowish brown, as found in the gingivae of 3 patients in the current study. According to Lin et al., from 34 children who underwent a liver transplantation under the age of 6 years, $61.3 \%$ with congenital biliary atresia presented green gingivae and tooth staining [23]. In the present study, 1 patient presented with both gingiva and tooth discolouration, and 2 presented with oral mucosa and tooth discolouration.

Other authors report that green or greenish brown dental discolouration results from biliverdin accumulation in dental tissues when cholestasis develops during tooth development $[22,24,25]$. Discolouration is a persistent lesion; once tooth development is completed, the tissues lose their metabolic activity and their ability to eliminate the pigment [25]. Structural changes in discoloured dentine were confirmed by histopathology [24, 25].

A tooth from a 3-year-old child with biliary atresia revealed extensive interglobular dentin, a number of faint yellow-brown lines contouring the developmental pattern, and a distinctive fluorescence [24]. Frequent cases of green dental discolouration (50-61.3\%) in children with hyperbilirubinaemia and biliary atresia were reported $[23,26]$. In the present study they occurred in all children with an early childhood medical history of jaundice. Physical examination of deciduous teeth revealed lesions in patients who had jaundice in their first year of life.

The study also confirmed frequent dental defects such as opacities and hypoplasia $(25.7 \%$ of the subjects). Studies assessing the prevalence of enamel defects in children with liver failure, or those following a liver transplant, vary. Seow et al. reported defects in all their study subjects with liver failure $(n=9)$; however, Hosey et al. reported this in only 6 out of 55 cases $[27,28]$. In transplant recipients, $19.18 \%$ presented with opacities [29]. Wondimu et al. reported opacities in $76 \%$, and enamel hypoplasia in $36 \%$ of paediatric liver recipients [26].

The present study showed a high prevalence and intensity of dental caries in both assessed patient groups.
At the same time, no correlation was found between the organ function, present enamel defects and dmf/dmfs and DMFt/DMFS. Dental caries research conducted by other authors in children before and after liver transplants differ in their results and are difficult to compare with those of the present report, which are related to multiple causes of caries [23, 26, 29, 30]. In the study by Yai et al. mean $\mathrm{dmft} / \mathrm{dmfs}$ scores for children aged $2-4$ years were $6.67 \pm 1.21 / 12.17 \pm 2.64$; in those aged 4-6 years the scores were $10.44 \pm 1.16 / 23.67 \pm 0.94$ [23]. In the present study, children showed a dmft score in deciduous teeth similarly high to the one presented by Yai et al., but Sheehy et al. found a significantly lower dental caries prevalence $(\mathrm{dmft} / \mathrm{dmfs}=1.22 / 2.35)$ [30]. Dental caries were significantly less intense in liver transplant patients. Wondimu et al. also reported that the prevalence of dental caries in paediatric liver recipients was not high (DMF/dmf $2.0 \pm 2.8$ ) [26]. Previous studies in Polish paediatric liver transplant recipients showed significantly higher $\mathrm{dmft} / \mathrm{dmfs}$ and DMFt/DMFs (respectively, 5.7/11.7 and 12.1/23.5), which illustrates the difficulty in comparing dental caries prevalence in different populations.

\section{Conclusions}

Oral mucosal lesions are commonly found in children with cirrhosis of the liver. Advanced liver disease promotes oral candidiasis. The severity of gingivitis correlates with the presence of dental plaque.

\section{References}

1. Ryckman FC, Alonso MH, Bucuvalas JC, et al. Liver transplantation in children. In: Liver disease in children. Suchy FJ, Sokol RJ (eds.) WF. Balistreri Lippincott Williams \& Wilkins, Philadelphia 2001; 949-75.

2. Jankowska I, Neuhoff-Murawska J, Socha P, et al. Clinical aspects of nutrition in children with chronic cholestasis - on the basis of a selected case [Polish]. Prz Gastroenterol 2008; 3: 139-42.

3. Hansen K, Horslen S. Metabolic liver disease in children. Liver Transpl 2008; 14: 391-41.

4. Golla K, Epstein JB, Cabay RJ. Liver disease: current perspectives on medical and dental management. Oral Surg Oral Med Oral Pathol Oral Radiol Endod 2004; 98: 516-21.

5. Novacek G, Plachetzky U, Potzi R, et al. Dental and periodontal disease in patients with cirrhosis: role of etiology of liver disease. J Hepatol 1995; 22: 576-82.

6. Pugh RN, Murray-Lyon IM, Dawson JL, et al. Transection of the oesophagus for bleeding oesophageal varices. Br J Surg 1973; 60: 646-9.

7. Lucey MR, Brown KA, Everson GT, et al. Minimal criteria for placement of adults on the liver transplant waiting list: a report of a national conference organized by the American Society of Transplant Physicians and the American Association 
for the Study of Liver Diseases. Liver Transpl Surg 1997; 3: 628-37.

8. Kamath PS, Wiesner RH, Malinchoc M, et al. A model to predict survival in patients with end-stage liver disease. Hepatology 2001; 33: 464-70.

9. Wiesner RH, McDiarmid SV, Kamath PS, et al. MELD and PELD: application of survival models to liver allocation. Liver Transpl 2001; 7: 567-80.

10. Kramer IR, Pindborg JJ, Bezroukov V, Infirri JS. World Health Organization. Guide to epidemiology and diagnosis of oral mucosal diseases and conditions. Community Dent Oral Epidemiol 1980; 8: 1-26.

11. Williams D, Kuriyama T, Silva S, et al. Candida biofilms and oral candidosis: treatment and prevention. Periodontology 2011; 55: 250-65.

12. Lewis MA, Samaranyake LP, Lamey PJ. Diagnosis and treatment of oral candidiosis. J Oral Maxillofac Surg 1991; 49: 996-1002.

13. Löe $\mathrm{H}$, Silness J. Periodontal disease in pregnancy. Acta Odont Scand 1963; 21; 533-5.

14. Clarcson JJ, O'Mullane DM. A modified DDE index for use in epidemiological studies of enamel defects. J Dent Res 1989; 68: 445-50.

15. Olczak-Kowalczyk D, Piróg A, Gozdowski D, Górska R. Zmiany na błonie śluzowej u dzieci i młodzieży z wtórnymi niedoborami odporności. Mag Stomatol 2012; 11: 56-60.

16. Grossman Sde M, Teixeira R, de Aguiar MC, et al. Oral mucosal conditions in chronic hepatitis C Brazilian patients: a cross-sectional study. J Public Health Dent 2009; 69: 168-75.

17. Pop TL, Nicolae Miu. Nutritional guidelines in children with cholestatic liver disease. Nutritional Therapy Metabolism 2010; 28: 117-28.

18. Kosel J, Kościuczuk U, Siemiątkowski A. The effect of nutritional treatment on immune function [Polish]. Prz Gastroenterol 2013; 8: 147-55.

19. Chang FY, Singh N, Gayowski T, et al. Staphylococcus aureus nasal colonization in patients with cirrhosis: prospective assessment of association with infection. Infect Control Hosp Epidemiol 1998; 19: 328-32.

20. Guggenheimer J, Close JM, Eghtesad B, et al. Characteristics of oral abnormalities in liver transplant candidates. Int J Org Transplant Med 2010; 1: 107-13.

21. Nellithady GS, Anila K, Kumar KK, et al. Lack of association of chronic liver disease in patients with oral lichen lanus. J Carcinogene Mutagene 2010; 1: 113.

22. Morisaki I, Abe K, Tong LS, et al. Dental findings of children with biliary atresia: report of seven cases. ASCD J Dent Child 1990; 57: 220-3.

23. Lin YT, Lin YT, Chen CL. A survey of the oral status of children undergoing liver transplantation. Chang Gung Med J 2003; 26: 184-8.

24. Majewski RF, Hess J, Kabani S, et al. Dental findings in a patient with biliary atresia. J Clin Pediatr Dent 1993; 18: 32-7.

25. Amaral TH, Guerra Cde S, Bombonato-Prado KF, et al. Tooth pigmentation caused by bilirubin: a case report and histological evaluation. Spes Care Dentist 2008; 28: 254-7.

26. Wondimu B, Nemeth A, Modeer T. Oral health in liver transplant children administered cyclosporin A or tacrolimus. Int J Pediatr Dent 2001; 11: 424-9.
27. Seow WK, Shepherd RW, Ong TH. Oral changes associated with end-stage liver disease and liver transplantation: implications for dental management. ASDC J Dent Child 1991; 58 : 474-80.

28. Hosey MT, Gordon G, Kelly DA, et al. Oral findings in children with liver transplants. Int J Paediatr Dent 1995; 5: 29-34.

29. Olczak-Kowalczyk D, Pawłowska J, Śmirska M, et al. Assessment of mineralized teeth's tissue status in developmental age patient after kidney or liver transplantation. Part II: Disturbances of hard teeth's tissue. Nowa Stomatologia 2008; 3: 86-91.

30. Sheehy EC, Heaton N, Smith P, et al. Dental management of children undergoing liver transplantation. Pediatr Dentistry 1999; 21: 271-80.

Received: $\quad 28.11 .2012$

Accepted: $\quad 19.11 .2013$ 